certain areas are picked out to the exclusion of certain other areas supplied by the same nerve.

On looking over the records of zoster, I find that Bryant describes a case nearly resembling, though more extensive than, the above, and that amongst Hutchinson's sixty-three recorded cases are lesions involving the first and second, the second, the second and third, and the third dorsal nerves, but not the one above described. In extending v. Bärensprung's nomenclature, I would suggest that to the above and similar cases the term "zoster pectoro-brachialis" be applied.

\section{Clinical 算otes:}

\section{MEDICAL, SURGICAL, OBSTETRICAL, AND THERAPEUTICAL.}

\section{SPINA BIFIDA AND HYDROCEPHALUS COMPLICATING PARTURITION.}

By W. M. Beauniont, M.R.C.S., L.S.A.

Mrs. P-, aged about thirty-five, a strong healthy woman, had been married four years when she became pregnant for the third time. There was nothing abnormal in the first or second confinement. On Dec. 1st she sent for me at 11 A.Mr., saying she had been ill all night. On $m y$ arrival the os was fully dilated and the membranes intact The breech was presenting and was quickly born, disclosing a spina bifida in the lumbar region, two or three of the spinal arches being absent. With very considerable difficulty the arms were brought down, and with some mancuvring and a good deal of traction (the pelvis fortunately being roomy) the head was delivered. The cause of the obstruction was a hydrocephalus of moderate dimensions-a condition which I had been unable to diagnose before birth. The child was a living female of average development otherwise, and survived its birth thirty-eight hours. There was a very large quantity of hair on the scalp, but none in the lumbar region. The occipito-frontal circumference measured fifteen inches and a half, but fortunately the parietal bones were very loose, and adapted themselves to the exigencies of parturition. The mother made an uninterrupted recovery.

In reviewing this case, I cannot help thinking that the spina bifida ought to have been sufficient clue to the nature of the obstruction. But hydrocephalus is seldom diagnosed before birth, even in head presentations. When the breech presents (and it is said to occur once in every five of these cases) the difficulties must be manifestly increased. Hydrocephalus is a rare complication of labour, and Playfair says it is one of great gravity to both mother and child. Dr. Keiller of Edinburgh, in seventy-four cases, found that rupture of the uterus occurred sixteen times. The usual treatment of tapping the head was not necessary in my case; but, had some operative measure been required, the question arises, Mright the fluid have been evacuated by opening the spina bifida? Tarnier in a case of hydrocephalus, with breech presenting, opened the vertebral column and passed in an elastic catheter, thus drawing off the intra-cranial fluid. The fact that it was necessary to pass in a catheter before the fluid could be evacuated seems to indicate that it would have been useless in my case to open the spinal cavity in the lumbar region, for there was no tenseness or bulging of the spina bifida. In a case of hydrocephalus complicated with spina bifida in the practice of Dr. McClintock, he found that the fluid in the head did not communicate with that in the vertebral sheath. With regard to the cause of this arrest of development I can say nothing. There was the usual history of a fright a month before delivery - that is, one would suppose, long after the arrest of development began. Patients find it so easy to explain everything. Perbaps that which is more to the point is the family history. One of the patient's sisters died insane in an asylum; another is the subject of hip disease; a brother, after breaking his ankle, suffered from disease of the jojnt, for which the foot had to be amputated. Of her two previous children, Mrs. $\mathbf{P}-$ lost one in convulsions, and the other also is subject to them. On the husband's side the family history is good.
CASE OF IMPERFORATE ANUS.

BY J. W. SMYTH, L.R.C.P., L.R.C.S.ED.

THE following case appears to me of sufficient interest to warrant publication.

Mrs.J _ - was delivered by me of a male child on Nor. 20th and on inquiry the following morning I found that it had not passed any motion by rectum, but that there were distinct traces of fæcal matter having been passed with the urine. On making an examination I found that $I$ had to deal with a complicated case of imperforate anus and connexion of the rectum with the bladder, and advised the child's removal to the hospital; but the parents not assenting to this, I operated myself. The mode of operation was as follows. I first pinched the child and made it scream, in order to find out if there were any bulging or appearance of bowel; but not finding any, 1 made a cut in the median line towards the coccyx, threequarters of an inch in length and a quarter of an inch in depth. I then passed my index-finger into the opening, using it as a director for my scalpel, and cut upwards in the direction in which I expected to find the bowel. Having worked my finger carefully upwards for about three inches without finding it, I passed a small catheter into the bladder per urethra until I found the point touch my finger. By carefully moving it about I was able to pass it through the bladder into the bowel, and with gentle pressure brought it down into contact with $m y$ finger. While my assistant held the catheter in its place, I cut down upon the point, upon which my little patient had a free evacuation from the bowels. Every day for a week I passed a large bougie, after which time, finding everything satisfactory, I discontinued it, and the child has been progressing as well as could be desired, having a free evacuation once or twice a day; and now, just two weeks after the operation, all discharge of fæcal matter with the urine has ceased. I consider that the early operation (just twentyfour hours after birth) accounts for the successful termination.

\section{CASE OF PLACENTA PRAVIA.}

BY C. R. OWEN, L.R.C.P.ED., M.R.C.S.

I was called in to see Mrs. C-, multipara, aged thirty, on Nov. 28th. She was about eight months pregnant, and had had a sudden discharge of blood, unaccompanied by pain. On examination I found that the os was thick and soft, and would admit of one finger. I could feel the placenta on the right side of the cervical zone of the uterus, and on pushing my finger a little beyond this could feel the head of the child. The hæmorrhage had been very slight, and had ceased. I prescribed, and ordered her to keep in bed, leaving instructions that I was to be called again if there was any return of the bleeding. I was sent for the next day, there having been a sudden renewal of the discharge, and in greater quantity. On examination I found the same condition of things as at first, with the exception that there was more hæmorrhage, with some clots. The os was dilated to about the size of a five-shilling piece, and slightly dilatable. I inserted my left hand into the vagina and the index finger into the uterus; the placenta and cord were easily felt, and beyond this the child's head and hand. The liquor amnii was intact. I gave the head a little tilt with my finger, and, as there were no pains, it easily bobbed up; and the arm was next treated in like manner. Then I could feel the foot through the mambrane; this I seized, at the same time breaking the sac, drew the foot down, and delivered. The child was born alive in about half an hour from my arrival, and with firm pressure on the uterus the placenta soon followed.

This is an ordinary case of placenta prævia, and I have had several like it; only in cases where the os has not been dilatable have I found them to be at all tedious; this can be overcome by using Barnes's bags, at the same time avoiding the danger of hæmorrbage. I fail to see the combination of complications your correspondent refers to in his case published in your issue of Nov. 26th, which seems similar to the foregoing, with the exception of the adberent placenta, which occurs to every practitioner, and is dealt with in the usual way. 